Journal of Nepal Mathematical Society (JNMS), Vol. 3, Issue 1 (2020); D.J.K.C., S.Ghimire

\title{
Basics and Structure of Project Writing in Mathematics
}

\author{
Durga Jang K.C. ${ }^{1}$, Santosh Ghimire ${ }^{2}$ \\ ${ }^{1}$ Central Department of Mathematics, Tribhuvan University, Kritipur, Kathmandu, Nepal. \\ ${ }^{2}$ Department of Applied Sciences and Chemical Engineering, Pulchowk Campus, Pulchowk, Tribhuvan University, Lalitpur, \\ Nepal. \\ Correspondence to: Santosh Ghimire, Email: santoshghimire@ioe.edu.np
}

\begin{abstract}
In this article various components of undergraduate project writing in mathematics are listed and discussed. We focus on the basics of a mathematical project writing in which we describe the necessity and usefulness of project writing. We then describe the structure of the project stating its various components. Finally we give some sample project topics. This article is intended for the students of bachelor level and faculties of mathematics among various universities in Nepal.
\end{abstract}

Keywords: Plagiarism, Referencing, Bibliography, Citation

DOI: https://doi.org/10.3126/jnms.v3i1.33000

\section{Introduction}

We begin with the famous quotation of Chief Justice Warren Earl Warren "Teachers and students must always remain free to inquire, to study, and to evaluate, to gain new maturity and understanding; otherwise our civilization will stagnate and die." [6] This describes the necessity of innovations and research activities in the society. Due to this reason every nation is continuously spending a large amount of their annual budget in promoting scientific research activities. These days scientific research is conducted in all areas which are directly or indirectly connected to the society. We can define research as "a careful investigation or inquiry specially through search for new facts in any branch of knowledge" 4. Thus, research is a logical and systematic search for new and useful information on a particular topic and the topic can be in any discipline. Moreover, it is an investigation of finding solutions to scientific and social problems through objective and systematic analysis. Information that is collected from different sources like experience, human beings, books, journals, nature etc can lead the discovery of hidden truth. Consequently, research leads to new contributions to the existing knowledge so that we can make progress in the field. Thus, the research ultimately determines the economic, social and political development of a nation.

Mathematics has been the integral part of every scientific research so that high priority is given to mathematical research. Mathematics comes in various areas mostly in natural science, social science and engineering. It is needed in different situations like tracing a rocket in space, designing a shoe, modeling front design of a car, beautifying a painting etc. Broadly the mathematics is the integral part of almost all areas and the research of these areas can be enhanced with the help of mathematics. Unfortunately in our context, the government has given the least priority to scientific research so that there are not many research projects in science and technology. Consequently, we don't see much research activities in mathematical sciences also. Due to this reason, mathematics has been limited mostly only in class room teaching so that students are not interested to pursue their degree in mathematics. This is reflected by the fact that mathematics graduates are decreasing in number every year. We can invoke the interest in mathematics if we can introduce research based activities in mathematics teaching. Introducing project writing at undergraduate level is a good way to motivate students in pursuing career in mathematics and its research. Considering this, Tribhuvan university (TU), the oldest university of the country, has recently introduced a project report for bachelor's degree. After taking an undergraduate math major in Tribhuvan university, a student has to write a project report (optional) to complete his bachelor degree in science and humanities. Most of the students prefer to take a final exam rather than writing a project. One of the reasons is that the students are not getting enough motivation from their faculties and even faculties are confused to supervise the project. Another reason why a student is not interested in mathematics or in its research is that the 
concerned people are not fulfilling their duties. Moreover, students are not getting enough motivations and information from the concerned people. In order to invoke the interest of mathematics and its research, we should be able to make them understand that there is good career in mathematics also. This article is mainly focused for the bachelor level students of various universities of Nepal, especially mathematics major. We expect that this article will be helpful for the students writing project report for their degree. Moreover, we believe that faculties will also be benefitted. So we first begin with basics of general project writing.

\section{Basics of Project Writing}

Here, we discuss the various benefits and importance of project writing. We also discuss a major component of research writing called plagiarism.

\subsection{Benefits and importance of project writing}

In this section, we discuss the various advantages and importance of writing a project. Project writing can be considered as the first step in the world of research. Readers are suggested to refer [2] and [3] for more about the basics of the research writing. Here we first summarize the benefits of conducting a research as:

- Person with a research degree gets a better employment, promotion, increase in benefits or even gets a position in various academic institutions and industries.

- They will be able to solve the existing unsolved and challenging problems

- They will acquire more respect and better recognition in their society.

- They will develop curiosity to find new useful things in real world so that a society can be benefitted.

There are numerous benefits of writing a project at the undergraduate level. These various advantages along with their importance are:

- It provides learning experience that enhances their knowledge

- It provides students with an opportunity to synthesize knowledge from various areas

- It enables students to acquire essential skills like collaboration, communication and independent learning

- It prepares students for lifelong learning and the challenges ahead

- It gives them the tolerance for obstacles

- It helps to understand to know how knowledge is constructed

- It builds up self confidence in students

- It helps students to clarify their career path

- It helps to improve the student's technical skill

- It helps to determine the area of interest

- It helps to integrate theory and practice

- It helps to analyze data

- It helps to understand the research process

- It helps to develop the skills for the interpretation of results

In the next section, we discuss about plagiarism. 


\subsection{Plagiarism}

The word plagiarism is very important term for every researcher and research-oriented person. All of the following actions are considered as plagiarism [5].

- turning in someone else's work as your own

- copying words or ideas from someone else without giving credit

- failing to put a quotation in quotation marks

- giving incorrect information about the source of a quotation

- changing words but copying the sentence structure of a source without giving credit

- copying so many words or ideas from a source that it makes up the majority of your work, whether you give credit or not

Next we discuss the structure of a standard project writing.

\section{Structure of Project Work}

The structure part is very important in every area of a formal writing. So structure also plays an important role in research writing. Every good piece of research should be written in a standard structure so that a reader can get all the information that an author intended to deliver. Due to this, structure is the major component in project writing too. In this section, we discuss in detail about the various necessary components of a standard project writing. The various components of a standard project writing are listed as:

1. Title and title page

2. Dedication

3. Copy right

4. Deceleration

5. Certificate of Approval

6. Acknowledge

7. Abstract

8. Table of Contents

9. List of Figure/table/symbols

10. Main body of the project

11. Conclusion

12. References and Bibliography 
We now describe these components in detail. We begin with title and title page.

\section{Title and title page}

Title is very important in project writing, so students and their advisors should give high effort to choose a title. At this level of mathematical writing, it is not expected from the students to obtain a new results or a breakthrough in the assigned topics. They are expected to study and understand the topics in full entirety and look for various applications in various areas. Some of the features of the title and title page are:

- This page contains short, descriptive title of the proposed project.

- Title should be fairly self-explanatory.

- It contains information about the author, institution, department and date of delivery.

- The main goal is to give clear understanding of the content.

\section{Dedication}

In this page, we write the various names of the people whom we want to dedicate our work.

\section{Copyright}

On this page, we write the name who has the copyright of the work.

\section{Deceleration}

Here, the author declares the whole project is his own work and has not been published anywhere else. Moreover, author also declares that any literature, data or works done by others and cited within this dissertation has been given due acknowledgment and listed in the reference section.

\section{Certificate of Approval}

In this page, evaluation committee members, supervisor, head of the department, internal and external examiner certify that the project work is satisfactory and meets the requirements and sign the page.

\section{Acknowledge}

In this page, author gives acknowledgement to all the person who helped him/her directly or indirectly in his/her project. This is an optional page. In general, authors acknowledge their project supervisor, head of the department, teaching faculties, their family members and friends.

\section{Abstract}

Abstract is very important in project writing and it is generally written at the completion of the entire work. A good reader can easily understand the entire project from its abstract. A good abstract states the brief summary of the project and should be written in simple declarative sentences. It gives a brief summary of how one wants to address the issue and includes a possible implication of the proposed work. One should note that an abstract should not review the report but should act as a sample of the contents of the project. In general its length should not exceed 200 words.

\section{Table of Contents}

Here, we list all headings and subheading with page numbers. This page does not include table of contents and abstract. 


\section{List of figure/table/symbols}

All the figures and tables used in the project are listed with their respective page numbers. Moreover, we also list all symbols that are used in the whole work with their description.

\section{Main body of the project}

In this section all the work of the project are included. This section of the project generally has three chapters and are listed below.

\section{(a) Chapter One:}

This chapter is also called the introduction chapter. In this chapter we mainly discuss the historical background and objectives of the proposed work. Various motivations of the project, its significance and scope are also discussed. We should also enlist or discuss the possible limitations of the project along with the difficulties during the work.

(b) Chapter Two:

This chapter is called the preliminary chapter where we give the details of all the mathematical principles behind the entire work relative to the project. The information collected from the literature reviews are kept in this chapter. Here, the author should describe the theoreti$\mathrm{cal} /$ mathematical principles behind the whole work relative to the project. Moreover, all the mathematical definitions, theorems, lemmas and examples which are used in the last chapter are stated. Proofs and details are also presented or referred from some sources. Methodologies of the work are also discussed in this chapter.

(c) Chapter Three:

This chapter is the main chapter of the project where we discuss the findings of the project. So this is the main body of the work and authors primarily focus on this chapter.

\section{Conclusions}

In this section, we review the entire work and present it in concise form.

\section{References and Bibliography}

In order to support and justify an idea in a project work, authors generally take the help of books, article, thesis etc. In return, authors have to thank authors of the used source. This is called referencing. Thus, referencing is simply a method of acknowledging and recognizing the authors for their innovative work. Similarly in some of the academic writings, Bibliography is used in the substitution of Reference list. There is a simple difference between bibliography and reference list. In the bibliography we list all the sources (books, articles, thesis, project, web-sites etc) that are referred in the main text and it also includes all the sources consulted even if they are not cited or refereed in the work for the future use. On the other hand, references only include the sources that are cited or referred in the work. A reference usually includes the name of author, date of publication, name and location of the publishing company, title of the journal or name of the book, title of the research or chapter's name. It is very important to refer to a source that has been used in the work. If someone's work is not referred, then it is plagiarism. So referencing helps to fight against plagiarism. In the project writing, referencing is done at two levels. At the first level we give a short reference in the body of the text and this is called in-text citation. At the second level a detailed reference is provided at the end of the project in the form of a list. While listing the sources, we follow alphabetical order of the last name of the author. If there are multiple authors, then we take the last name of the first author. Journal articles and most books are peer reviewed and can be referred whereas one has to be careful in taking information from websites. For example, matters taken can not be referred from the source wikipedia. Nowadays referencing has become an integral element of academic writing which is used to locate the original source of work so that the readers of the project may access the material and understand it in their own way. Now we discuss the various referencing styles. 


\section{Referencing Styles}

There are various standard referencing styles available. In general, the institutions or publishing houses decide their referencing style so that the referencing styles vary with publishing houses. The commonly and widely used referencing styles are listed below:

1. Vancouver

2. Harvard

3. APA (American Psychological Association)

4. MLA (Modern Language Association)

5. Chicago

6. ACS (American Chemical Society)

7. AGLC (Australian Guide to Legal Citation)

8. AMA (American Medical Association)

9. CSE (Council of Science Editors)

10. IEEE (Institute of Electrical and Electronics Engineers)

11. AMS (American Mathematical Society)

The above mentioned referencing styles differ in the order of information, use of punctuation, in formatting and these differences occur in both the level of referencing. Readers are suggested to refer to [1 for more information about referencing and bibliography. For mathematics, we use AMS style of referencing. We now give the details of referencing in AMS style for various sources. In AMS style of referencing, in-text citation is simply done by the number in the square bracket where the number corresponds to the position it appears in the reference list.

We follow the following sequence to list the article in the reference list.

1. Author's first name and last name

2. Title of article (in italics)

3. Journal Title

4. Volume Number (Year of Publication)

5. Page

6. DOI number (if exists)

We follow the following sequence to list the book, thesis, project in the the reference list.

1. Author's first name and last name

2. Title (in italics)

3. Name of the publisher

4. City of Publication

5. Year of Publication

Using the above style, we now show the listing of an article and a book in the reference list.

1. S. Ghimire and C. N. Moore, A Lower Bound in the Tail Law of the Iterated Logarithm for Lacunary Trigonometric Series, Proceeding of American Mathematical Society, 142(9), 3207-3216.

2. James Stewart, Calculus: Early Transcendental, USA, Cengage Learning, 2008. 
Readers are suggested to read [1] for more about AMS style of referencing. Now we give the evaluation scheme to evaluate a project writing in mathematics.

1 Introduction of the topic- $10 \%$

2 Presentation-15\%

3 Organization- $15 \%$

4 Figure/Plots/Tables/Symbols-5\%

5 Content- $60 \%$

(i) Originality and creativity-15\%

(ii) Literature Review-10\%

(iii) In-depth Research- 15\%

(iv) Analysis and logical argument/presentation- 15\%

(v) Conclusion/Findings- 5\%

\section{Project Work in Mathematics}

In this section, we discuss the project in the context of mathematics. At the beginning of the project writing in mathematics, a student has to choose an area in which he/she wishes to write a project. The student should be familiar with the various branches of mathematics. The various branches of mathematics are listed in alphabetical order:

- Algebra ( Linear, Multilinear, abstract, Elementary)

- Arithmetic (Number Theory)

- Calculus (Analysis, Differential Equations, Dynamical Systems,Numerical Analysis, Optimization, Functional Analysis)

- Geometry (Discrete, Algebraic, Analytic, Differential, finite, topology, trigonometry )

- Foundations (Philosophy of mathematics, Mathematical Logic, Set theory, Category theory)

- Applied (Mathematical Physics, Probability, Mathematical Statistics, Statistics, Game theory, Information theory, Computer Science, Computational, Control theory)

- History of mathematics, Mathematics and art

- Mathematics Education, Order theory, Graph theory

After the successful completion of the project writing in mathematics, the various benefits are:

- It increases the mathematical understanding of the students. More precisely, it helps students understand a specific math concept or idea by doing in-depth study of these concepts.

- It develops confidence in students while studying or teaching mathematics.

- They will enjoy doing mathematics.

- They will develop problem solving skills.

- They will develop creative and imaginative approaches to understand mathematics.

The mathematics projects can be written in a number of ways. Some of the ways are: 
- To in-depth study of a widely used theorem and its consequences.

- To solve a real life problem.

- To solve a problem arising in other disciplines.

- To study how a concept is used to create a new knowledge.

- To study the history of various mathematicians.

The faculties who supervise the math projects are equally responsible to complete the project. There are basically three different roles of a supervisor in project writing. He works as resource provider, becomes a co-learner, and also as facilitator and counselor. It is very important that faculties who supervise the math projects have to ensure that students have a complete and deep understanding of the chosen topic of the project. Most importantly the supervisor should have good knowledge of the mathematical subject matter. The various roles of the supervisor are listed as:

- help students select a mathematical topic

- help students generate ideas through brainstorming

- guide students to formulate their project objectives

- help students gather ideas, define objectives, draw up the schedule and provide input for language skills

- intervene if student's direction not practical

- offer suggestions to solve problems

- center on what students learned during the project

- share the reflection

- provide a balanced picture of strengths and weaknesses

- offer suggestions for improvement

- plan the project with the student

- read the work at most in chapters

- use different colored ink to add comments

- before submission, the recommended corrections must be implemented

Finally, we give various possible topics for future project writing in mathematics:

- First order differential equations and its various applications in real world.

- The relevance of the use of the method of undetermined coefficients for solving differential equations

- The application of linear programming in profit maximization

- Studying different numerical methods in solving first order differential equations

- Numerical methods for solving partial differential equations

- Modeling the effects of carriers on transmission dynamics of infectious diseases

- An exploration and analysis of mathematics as a tool in the arts

- Linear and non-linear sampling theory with applications to current problems in communications

- Use of calculus in business 
- Contribution of Leibnitz in mathematics

- Fibonacci numbers in nature

- Golden ratio

- Laplace transform and its applications

- Applications of Z-transform in engineering

- A study on internet mathematics

- Mathematics and sound

- Random Walks

- The development of matrix theory

- Ito's integral

- Stochastic processes and their applications to mathematical finance

- How is Lagrange's theorem related to RSA cryptography?

- The application of fractional calculus in mathematics and physics

- Statistical modeling for data that are dependent in space and/or time.

- How was algebra invented?

- Relationships between theorems of linear algebra and matrix theory

- A study on the Lotka-Volterra equations and the undamped pendulum

- Numerical error in Euler's method

- Qualitative behavior of systems with eigenvalues

- Qualitative analysis of autonomous systems

- Population dynamics

- Hamiltonian and dissipative systems

- Discrete logistic equation

- Mathematics behind Bungy jumping

Acknowledgement: We first of all thank Nepal Mathematical Society for motivating us to deliver a talk on the project writing in mathematics which consequently made us to formalize the talk as an article. Our sincere thanks goes to Prof. Dr. Chet Raj Bhatta, President of Nepal Mathematical Society. We would also like to thank Prof. Dr. Pushpa Raj Adhikari, Prof. Dr. Prakash Muni Bajracharya, Prof. Dr. Dil Bahadur Gurung, Dr. Ajay Singh, Dr. Shreeram Khadka, Dr. Samir Shrestha, Dr. Jeevan Kafle and all the faculties and participants of the Nagarkot Workshop 2019, organized by Nepal Mathematical Society, for their help in preparing this article. We benefitted a lot from the workshop presentations and discussions. 


\section{References}

[1] Alvi, M. H., 2016, A Manual for Referencing Styles in Research, https://www.researchgate.net/publication/308786787.

[2] Rajesekar S., Philominathan, P. and Chinnathambi, V. Research Methodology https://arxiv.org/abs/physics/0601009v3

[3] Saxena V. P., 2013, Lecture Notes on Research Methodology, Indra Publishing House, India.

[4] The Advanced Learner's Dictionary of Current English, Oxford, 1952, p. 1069.

[5] Webpage https://www.plagiarism.org/article/what-is-plagiarism.

[6] William, K. and Lee, B., 2013, The Law of Higher Education Fifth Edition, John Wiley and Sons. 